\title{
Influence of landscape factors and management decisions on spatial and temporal patterns of the transmission of chronic wasting disease in white-tailed deer
}

\author{
Marilyn O’Hara Ruiz', Amy C. Kelly², William M. Brown¹, Jan E. Novakofski³, Nohra E. \\ Mateus-Pinilla ${ }^{4}$ \\ ${ }^{1}$ Department of Pathobiology, University of Illinois, Urbana, IL, USA; ${ }^{2}$ National Institute of Diabetes and \\ Digestive and Kidney Diseases, National Institutes of Health, Bethesda, MD, USA; ${ }^{3}$ Department of Animal \\ Sciences, University of Illinois, Urbana, IL, USA; ${ }^{4}$ Illinois Natural History Survey, Prairie Research Institute, \\ University of Illinois, Champaign, IL, USA
}

\begin{abstract}
Chronic wasting disease (CWD) has been reported in white-tailed deer at the border of the US states of Illinois and Wisconsin since 2002. Transmission of infectious prions between animals and from the environment has resulted in spatial and temporal structure observable in the spatio-temporal patterns of reported cases. Case locations of 382 positive cases from 28,954 deer tested between 2002 and 2009 provided insight into the potential risk factors and landscape features associated with transmission using a combination of clustering, generalised linear modelling and descriptive evaluations of a risk map of predicted cases of CWD. A species distribution map of white-tailed deer developed using MaxEnt provided an estimate of deer locations. We found that deer probability increased in areas with larger forests and less urban and agricultural lands. Spatial clustering analysis revealed a core area of persistent CWD transmission in the northern part of the region. The regression model indicated that larger and more compact forests were associated with higher risk for CWD. High risk areas also had soils with less clay and more sand than other parts of the region. The transmission potential was higher where landscape features indicated the potential for higher deer concentrations. The inclusion of spatial lag variables improved the model. Of the 102 cases reported in the study area in the two years following the study period, $89(87 \%)$ of those were in the $32 \%$ of the study area with the highest $50 \%$ of predicted risk of cases.
\end{abstract}

Keywords: chronic wasting disease, landscape epidemiology, white-tailed deer, environmental transmission, prion, USA.

\section{Introduction}

Chronic wasting disease (CWD) has been identified in deer (Odocoileus species), with fewer cases found in Rocky Mountain elk (Cervus elaphus) and in moose (Alces alces) (Sigurdson, 2008). It is one of several known transmissible spongiform encephalopathies (TSE), associated with the presence of transmissible protease-resistant prion proteins (PrP). The TSEs include bovine spongiform encephalopathy (or mad cow disease), variant CreutzfeldtJakob disease in humans and scrapie in sheep. CWD and scrapie are similar in that both horizontal and environmental transmission of infection have not been observed with other TSEs, where direct ingestion is the common transmission pathway (Miller and Williams, 2003; Johnson et al., 2006; Seidel et al., 2007; Saunders et al., 2012).

\footnotetext{
Corresponding author:

Marilyn O'Hara Ruiz

Department of Pathobiology, University of Illinois

2001 South Lincoln Avenue, Urbana, IL 61802, USA

Tel. +1 217 265-5115; Fax +1 217 244-7421

E-mail: moruiz@illinois.edu
}

There is no vaccine or cure for this fatal neurodegenenerative disease, and public health officials advise against eating meat from infected animals. Special care is advised when handling tissues harvested from known CWD areas, and this is especially important when handling brain and spinal cord tissues (Belay et al., 2004). CWD surveillance and control measures have been implemented across the USA and Canada. These measures focus on a reduction in disease transmission and spread, mitigation of the negative economic consequences of reduced recreational hunting, protection of captive herds of cervids and reduction of the potential for cross-species transmission of the prions that cause CWD (Williams, 2005; Joly et al., 2009; Wasserberg et al., 2009).

CWD was first recorded in mule deer in a Colorado research facility in 1967 (Williams and Young, 1980). It was subsequently seen in free-ranging deer and elk at least by 1981 (Spraker et al., 1997). Movement of infected farmed elk may have played a role in the spread of CWD to other farmed and free-ranging cervids (Enserink, 2001). In an apparent range expansion, in 2002, a case of CWD was reported for the first time in Wisconsin in a hunterharvested deer (Joly et al., 2003). Since 2002, cases in 
free-ranging animals have been reported as far east as New York state, southward to Mexico, and in the western Canadian provinces of Saskatchewan and Alberta (Sigurdson, 2008). By the end of 2012, the largest foci of CWD in both captive and free-ranging animals in North America centred on: (i) the intersection of the states of Colorado, Nebraska and Wyoming; (ii) southern Wisconsin and northern Illinois; and (iii) the province of Saskatchewan with some spillover to Alberta (USGS, 2012).

Transmission of the prion from infected to uninfected hosts has been attributed to a combination of horizontal transmission of abnormal prion protein between deer or indirect transmission from environmental sources, with limited evidence for maternal (vertical) transmission patterns (Miller and Williams, 2003). Blood, saliva, urine and faeces of infected animals are potential sources of CWD infection within a herd (Sigurdson et al., 1999; Mathiason et al., 2006; Haley et al., 2009; Tamgüney et al., 2009). Additional laboratory evidence demonstrated that both skeletal muscle and central nervous system tissues are important sources of prions that can result in CWD (Angers et al., 2006).

Infection can be acquired from the environment during grazing via soil ingestion, through dust inhalation or via contact with infected biological material where prions bound to soil may be an important source of CWD (Miller et al., 2004; Gough and Maddison, 2010). Prions in urine, faecal material or from an infected carcass can enter the environment and remain infectious for long periods (Miller et al., 2004; Haley et al., 2009; Saunders et al., 2012). Prions bind strongly to various types of soil and resist removal by water or various solvents (Leita et al., 2006; Saunders et al., 2008) so though possibly long-lasting, there is little subsequent migration or leaching through the soil (Jacobson et al., 2010; Maddison et al., 2010). Prions may interact with various components of soil including clay, sand and organic components (Ma et al., 2007; Maddison et al., 2010; Saunders et al., 2010). In vitro and laboratory assays have indicated that prions bound to clays may have greater infectivity (Johnson et al., 2006) while field studies by Walter et al. (2011) showed an association between CWD in mule deer and a higher percentage of clay soils within the deer's home range. A study of scrapie and BSE in Great Britain found a spatial correlation between these two diseases and increased $\mathrm{pH}$ and organic carbon in soils but nothing discernable related to clay particles (Imrie et al., 2009).

It is possible that the binding properties of certain metals have an effect on CWD susceptibility in individual deer and that these effects may be protective when combined with specific coding polymorphisms in white-tailed deer (Kelly et al., 2008). Copper $(\mathrm{Cu})$, in particular, binds with the prion protein, but the relation with transmission and disease status is not clear (Millhauser, 2007). Manganese in soil strongly stabilises prion against degradation and also increases infectivity (Davies and Brown, 2009).

Spatially, higher prevalence of CWD has been observed in core areas relative to adjacent regions. Joly et al. (2006) delineated a core area of infection within the deer elimination zone in Wisconsin where prevalence declined isotropically at larger distances from the core area. Typically, there is persistence in the location of core areas over time. This has been seen in Wisconsin (Joly et al., 2003; Osnas et al., 2009), as well as in Colorado (Miller and Conner, 2005). In Colorado, there was a higher prevalence among animals in winter range areas, where density of animals is higher than other periods, suggesting the possible role of deer behaviour in CWD transmission (Conner and Miller, 2004). In Illinois CWD prevalence was higher in conditions of lower human population, more silt loam soils, flatter areas and places with larger forests (Mateus-Pinilla et al., 2013). In the Illinois study, the environmental factors were covariates in an analysis that evaluated the effect of deer reduction on CWD prevalence, and they were not fully examined relative to CWD transmission potential.

In this analysis, we measured and described the spatial and temporal dynamics and ecological and management factors related to an outbreak of CWD in white-tailed deer during the years from 2002 to 2009 in a region extending from northern Illinois to southern Wisconsin, USA (Fig. 1). CWD was first detected in Wisconsin in 2002 from deer harvested in 2001 and then in Illinois in the fall of 2002 (Joly et al., 2003). The objectives of this study were to address the following four questions: First, what is the dominant spatial distribution of CWD in the IllinoisWisconsin border region and has it changed over time? Second, what landscape features are associated with diseased deer in a natural setting? Third, what potential CWD transmission routes are suggested through these results? Fourth, what characterises the potential new areas of disease transmission?

\section{Materials and methods}

\section{Basic CWD data}

Data on tested deer were obtained from the Illinois and Wisconsin Departments of Natural Resources. Within the study area during this period there were 382 confirmed cases from 28,954 tests for CWD in free-ranging white-tailed deer. Data included the date of harvest, the age and sex of the deer and the loca- 
tion of harvest. The age of each deer was coded as fawn, juvenile or adult. Harvest methods were not recorded consistently across the two states, but the tested samples included hunter harvests, focused deer reduction programmes, including sharp-shooting for CWD control and incidental collection of suspect or vehicle-killed deer. For each deer tested, the harvest location was recorded as the "section" as defined by the United States Public Land Survey System. This geographical unit is referred to as the TRS, for township / range / section and is approximately $1 \mathrm{mi}^{2}$ $\left(2.59 \mathrm{~km}^{2}\right)$ in size.

\section{Study area}

We delineated the $9,798 \mathrm{~km}^{2}$ study area by drawing a minimum convex polygon that encompasses virtually all the reported cases of CWD during the study period in Illinois and cases in the Wisconsin counties near the Illinois border. There were 3,979 TRS in the study region. While this area encompasses the majority of CWD cases reported in Illinois, for this analysis, we included only the Wisconsin cases clustered closely to the Illinois cases and did not include a much larger Wisconsin outbreak to the northwest (Fig. 1). For the purpose of this analysis, each year started on July 1 and ended on June 30 of the following year, encompassing sequential fall and early winter hunting seasons and the winter culling season in a single year. The 7-year study period was from July 1, 2002 to June 30, 2009, referred to as the years 2003 to 2009.

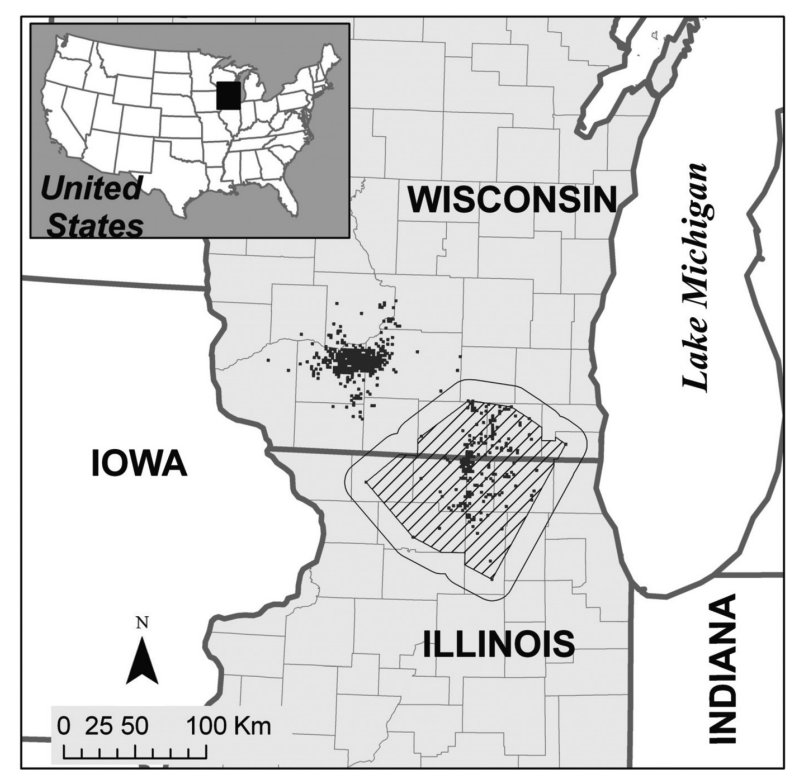

Fig. 1. Study area in Wisconsin and Illinois. The crosshatched shape with $15 \mathrm{~km}$ buffer is area of analysis. The black points are at TRS where deer have tested positive in the area.
To focus the analysis where deer are more likely to be found, we developed a species distribution model of white-tailed deer. For this, we used the TRS locations of all tested deer $(\mathrm{N}=28,954)$ and a set of environmental variables (described below) in an ecological niche model (Peterson, 2006). This model was developed using the MaxEnt software, which employs a machine-learning approach to predict the geographical distribution of a species based on presence-only data (Elith et al., 2011). The estimate was used to identify landscape characteristics associated with deer populations, and provided an empirical measure to eliminate from the risk map development the areas not suitable for ongoing support of deer populations.

\section{Spatial and temporal patterns of CWD}

We developed a structured description of the spatial and temporal patterns of positive tests for CWD with three measures for spatial and space-time clustering: Moran's I, Getis $\mathrm{G}^{*}$ and the Kulldorff scan statistic. We used ArcGIS (ESRI; Redlands, USA) version 10 to measure the Moran's I and Getis G*. The Moran's statistics were calculated at incremental distances on the percentage of positive tests by TRS as well as on the counts of cases by TRS. The Getis G* was measured on the number of cases by TRS. Then, we defined space-time clusters based on data for individual deer with the software SaTScan version 9.1 (Kulldorff, 1997). In SaTScan, we used the discrete Poisson model on the count of positive tests for CWD relative to all tests and controlling for age and sex of each animal tested. The geographical location was the TRS and temporal unit was year of harvest. The maximum size of clusters was $20 \mathrm{~km}$ and the maximum time was 3 years. The output was a set of circular regions encompassing the areas where the number of cases of CWD observed for that area and time period and given the demographic characteristics of deer was greater than expected. Probability values were assigned to the clusters based on a maximum likelihood ratio compared to 999 random replications and Monte Carlo testing.

Regression model on CWD and environmental risk factors

We examined environmental factors to measure the landscape characteristics potentially related to the spatial pattern of transmission of CWD using a generalized linear model (GLM) approach. For this analysis, we used a negative binomial regression model. The 
negative binomial option with a loglinear link function was chosen due to its suitability in modelling counts and its appropriateness for estimating models with over-dispersion (Breslow, 1984). The statistical analysis was carried out in IBM SPSS Statistics, version 20 (Armonk, USA). The response variable was the count of CWD cases reported for the years 2003 to 2009. An offset variable was the probability of deer in the TRS as measured from the deer distribution model. Environmental factors included measures of terrain, land cover and use, forest characteristics, soil composition, human population density and distance from water bodies, rivers and streams (Table 1). These data were scaled to the TRS with ArcGIS to create scale-compatible environmental variables for each TRS. For data reduction of the often-correlated environmental factors we used principal components analysis (PCA) to create a set of uncorrelated factors that measured the main features of the study area (Legendre and Legendre, 1998). The PCA terms were subjected to varimax rotation for better interpretability and we selected only principal components with Eigenvalues greater than 1 .

The regression model also took into account the effect of management of CWD by including variables on deer test intensity and the State of harvest. Intensity of testing was a binary variable with a value of " 1 " when the total tests per TRS from 2003 to 2009 was in the $75^{\text {th }}$ percentile (13 or more tests) and a " 0 " otherwise. The state of harvest variable was " 1 " for Illinois TRS and "0" for Wisconsin. We also used a spatial lag variable of the dependent variable to measure the degree to which CWD cases were near other cases and considered the effect of spatial lag on the relevant predictor variables in the model. Independent variable selection minimised the Akaike's information criterion (AIC) value (Burnham and Anderson, 2002). It was based on the evaluation of the effect on other covariates of adding each variable to the model, and by using a probability value of $\mathrm{p}<0.1$ for the significance cut-off for the covariates to be retained during model development and $\mathrm{P}<0.05$ for inclusion in the final model.

Finally, we evaluated the model's predictions for cases of CWD compared to the locations of cases reported during the two years following the test data: 2010 and 2011. We identified the TRS where CWD was found during these subsequent years but where intensive testing had not been carried out in prior years and TRS where the model indicated conditions associated with cases, but where no cases have yet been found. The purpose of this evaluation was both to assess the validity of the model and to translate the results for resource management purposes. To aid in this effort, we assessed specific environmental characteristics of a TRS relative to its predicted probability of having cases of CWD.

Table 1. Environmental variables used to characterise the study region.

\begin{tabular}{|c|c|c|}
\hline Variable $^{\mathrm{a}}$ & Measured for each TRS as & Source (data type) \\
\hline $\begin{array}{l}\text { Land cover } \\
\text { Agriculture } \\
\text { Urban } \\
\text { Forest }\end{array}$ & $\begin{array}{l}\% \text { of land in agriculture } \\
\% \text { of urban land } \\
\% \text { of forested land } \\
\text { Forest segments no./size }\left(\mathrm{km}^{2}\right) \\
\text { Average, maximum and minimum forest size }\left(\mathrm{km}^{2}\right) \\
\text { Compactness: maximum perimeter to area ratio } \\
\% \text { and standard deviation of canopy cover }\end{array}$ & $\begin{array}{l}\text { US Geological Survey } \\
\text { National Land Cover Database, } 2001 \\
\text { (land use, land cover, tree canopy) }\end{array}$ \\
\hline $\begin{array}{l}\text { Terrain } \\
\text { Slope } \\
\text { Elevation }\end{array}$ & $\begin{array}{l}\text { Average and standard deviation } \\
\text { Average and standard deviation }\end{array}$ & $\begin{array}{l}\text { US Geological Survey } \\
\text { (digital elevation model) }\end{array}$ \\
\hline $\begin{array}{l}\text { Soil } \\
\text { pH } \\
\text { Clay, silt and sand } \\
\text { Organic matter }\end{array}$ & $\begin{array}{l}\text { Weighted average } \\
\text { Weighted average } \\
\text { Weighted average }\end{array}$ & $\begin{array}{l}\text { US Department of } \\
\text { Agriculture Soil Survey } \\
\text { (geographic database) }\end{array}$ \\
\hline $\begin{array}{l}\text { Human population } \\
\text { Population density }\end{array}$ & Weighted average & $\begin{array}{l}\text { US Census Bureau } 2000 \text { Census } \\
\text { (blockgroup level population) }\end{array}$ \\
\hline $\begin{array}{l}\text { Hydrography } \\
\text { Large rivers, perennial streams and water bodies }\end{array}$ & Average distance from the feature & $\begin{array}{l}\text { US Geological Survey } \\
\text { (national hydrography dataset) }\end{array}$ \\
\hline
\end{tabular}

${ }^{a}$ Each variable was processed so that it was measured for each of the geographic units. The units were sections of approximately 1 square mile in size as defined by the United States Public Land Survey System and are referred to here as a TRS. 


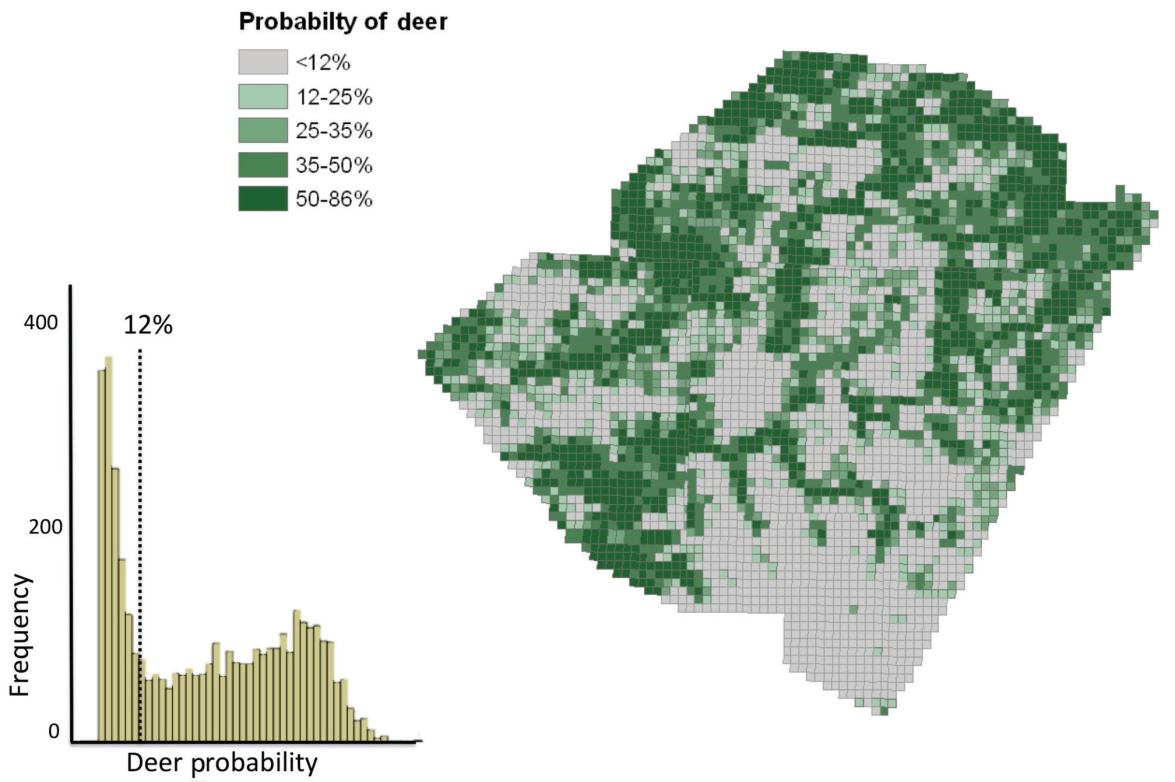

Fig. 2. Results of Maxent ecological niche model with estimates for the probability of deer being present. Places with probability greaten than $12 \%$ were included in the regression model.

\section{Results}

\section{Species distribution}

The MaxEnt ecological niche model estimated the probability of deer in each TRS with an ROC area under the curve value for the test data of 0.770 . The variables that contributed the most to the model were percent forest $(65 \%$ contribution), maximum forest size $(14 \%)$ and percent urban $(7 \%)$. Based on the distribution of the probability of a TRS having deer, all values of less than $12 \%$ were excluded for the model development for CWD (Fig. 2). The subset area used in subsequent analyses comprised 2,555 TRS. The areas that were excluded were clearly more urban, more agriculture and less forested than those used in the analysis (Table 2). Of the 382 reported cases of
CWD $15(3.9 \%)$ were in a TRS with lower than $12 \%$ or lower probability of being suitable for deer. These 15 cases were all in TRS with a single case of CWD and they were omitted from the regression analysis.

\section{Temporal, spatial and spatio-temporal patterns}

Of the 27,631 deer tested in the study region subset area, 367 deer tested positive for CWD (1.4\%). Neither the number of cases per year nor the prevalence by year exhibits a clear temporal trend (Fig. 3a). The number of tests that were carried out from year to year varied considerably, with over 6,000 tests in 2007 compared to about half that amount in 2009. In Illinois, the level of testing was more consistent across years than in Wisconsin. The spatial autocorrelation (SA) observed in the number of cases of CWD by TRS

Table 2. Summary of study area land use, testing intensity and cases of CWD in deer, 2003-2009.

\begin{tabular}{|c|c|c|c|c|c|c|}
\hline Deer probability & TRS (no.) & $\begin{array}{c}\text { No. of cases } \\
\text { (range per TRS) }\end{array}$ & $\begin{array}{c}\text { Average forest } \\
(\%)\end{array}$ & $\begin{array}{c}\text { Average urban } \\
(\%)\end{array}$ & $\begin{array}{c}\text { Average agriculture } \\
(\%)\end{array}$ & $\begin{array}{l}\text { Average forest size } \\
\qquad\left(\mathrm{km}^{2}\right)\end{array}$ \\
\hline $\begin{array}{l}\text { Less than } 12 \% \\
\text { (not in model) }\end{array}$ & 1,424 & $15(0-1)$ & 1.1 & 12.5 & 79.9 & 0.27 \\
\hline $\begin{array}{l}12 \text { to } 50 \% \\
\text { (in model) }\end{array}$ & 1,549 & $104(0-7)$ & 8.2 & 6.3 & 75.3 & 2.38 \\
\hline $\begin{array}{l}\text { Greater than } 50 \% \\
\text { (in model) }\end{array}$ & 1,006 & $264(0-17)$ & 26.6 & 2.7 & 60.1 & 10.01 \\
\hline Total & 3,979 & $382 *$ & 10.3 & 7.6 & 73.0 & 8.6 \\
\hline
\end{tabular}

\footnotetext{
*The number of cases in the total amount is one less than noted elsewhere due to a case without full location information.
} 
(A)

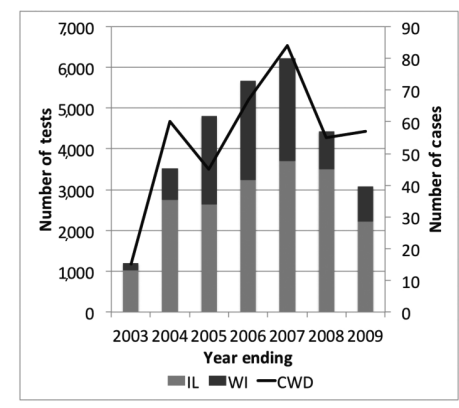

(C)

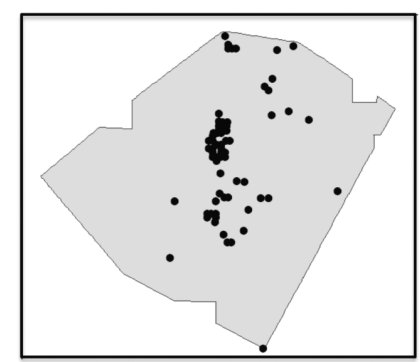

(B)

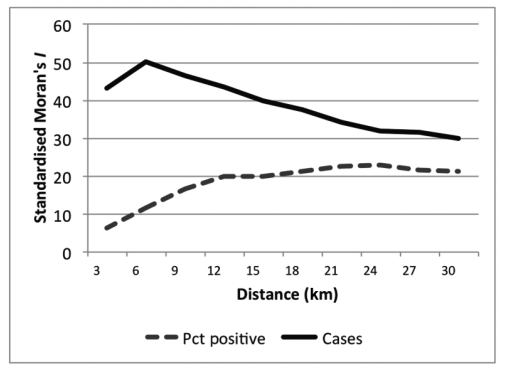

(D)

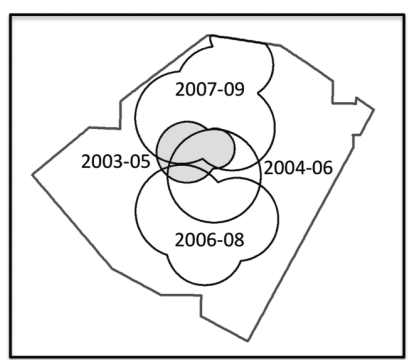

Fig. 3. Spatial and temporal trends in CWD cases. (A) Number of tests and number of cases by state and by year; (B) Moran's $I$ measure at incremental distances for percentage of positive tests and for number of cases by TRS; (C) Getis Gi* outcome measured on number of CWD cases for all years combined; (D) Space-time clusters defined with a discrete Poisson model space-time retrospective analysis using SaTScan while controlling for age and sex.

was very high for the nearest neighbour TRS, up to about $6 \mathrm{~km}$, and then declined gradually (Fig. 3b). The same SA test performed on the percentage of positive tests indicates a more broadly structured pattern with SA increasing gradually up to a distance of about 10 $\mathrm{km}$ and then remaining stable through at least $30 \mathrm{~km}$ (Fig. 3b). Spatially, TRS with more cases of CWD than would be expected statistically are cantered in a line going north to south in the study area with the strongest concentration TRS with cases in the centre of this area (Fig. 3c). The output from the SaTScan Poisson model of spatio-temporal cluster analysis revealed a pattern of clustering of cases in the centre of the region in the early part of the period, from 2003 to 2005 , with an expansion of that region starting in 2004 (Fig. 3d). There was marked expansion to the south starting in 2006. The period starting in 2007 showed an expansion to the north. The core area at the centre of the region was a focal area of higher numbers of cases throughout the study time period.

\section{Environmental analysis}

The 2,555 TRS in the study area subset were included in the CWD risk model development. From the PCA analysis of 17 environmental variables we retained six factors that explained $80 \%$ of the variance in the original variables (Table 3).
The following six factors were associated with these characteristics in the study region:

(i) less agriculture, more forest and more compact forests;

(ii) more rugged areas, i.e. with more presence of steeper slopes and with variability of slope and elevation;

(iii) forest size is larger;

(iv) far from larger rivers and with higher elevation;

(v) highly urban or densely populated (human); and

(vi) less organic matter in soils and farther from streams.

The variables for selected soil characteristics were not included in the PCA described above so that we could consider each soil variable separately. Further, the correlation between clay and silt was very high $(r=0.88)$. Thus, silt was not included. The number of forest segments per $\mathrm{km}^{2}$ and the average distance from a lake or pond did not load on any of the factors, so these were also considered separately as covariates.

The initial regression model with 11 environmental covariates: factors 1-6, clay, sand, soil $\mathrm{pH}$, number of forest segments and distance to water bodies had an AIC of 1,958 and a likelihood ratio $\chi^{2}$ of 166 $(\mathrm{P}<0.001)$. In the second stage of model development, the six statistically important covariates from model 1 (factor 1, factor 3, factor 5, factor 6, clay, and forest 
Table 3. Factor loading on environmental variables for the six component factors used as predictor variables in the regression model development.

\begin{tabular}{|c|c|c|c|c|c|c|}
\hline \multirow{2}{*}{ Variable } & \multicolumn{6}{|c|}{ Component } \\
\hline & 1 & 2 & 3 & 4 & 5 & 6 \\
\hline$\%$ agriculture & -0.777 & -0.188 & -0.118 & 0.052 & -0.454 & 0.060 \\
\hline$\%$ forest & 0.871 & 0.246 & 0.268 & -0.058 & -0.032 & -0.062 \\
\hline$\%$ canopy & 0.871 & 0.270 & 0.266 & -0.047 & 0.034 & -0.048 \\
\hline SD canopy & 0.915 & 0.207 & 0.088 & -0.062 & -0.008 & -0.014 \\
\hline Compactness* & -0.825 & -0.038 & -0.205 & 0.073 & 0.041 & -0.051 \\
\hline Average slope & 0.189 & 0.922 & 0.061 & 0.073 & -0.072 & 0.037 \\
\hline SD slope & 0.441 & 0.756 & 0.148 & 0.037 & 0.090 & -0.018 \\
\hline SD elevation & 0.188 & 0.899 & 0.030 & 0.022 & -0.005 & 0.021 \\
\hline Average forest size & 0.275 & 0.079 & 0.940 & -0.110 & -0.027 & 0.004 \\
\hline Maximum forest size & 0.330 & 0.019 & 0.705 & -0.190 & -0.070 & 0.038 \\
\hline Minimum forest size & 0.118 & 0.093 & 0.883 & -0.011 & 0.026 & -0.025 \\
\hline Average elevation & -0.068 & 0.055 & -0.136 & 0.869 & -0.043 & 0.137 \\
\hline Distance to large rivers & -0.104 & 0.045 & -0.086 & 0.869 & -0.092 & -0.078 \\
\hline$\%$ urban & 0.132 & -0.040 & -0.093 & -0.051 & 0.834 & 0.078 \\
\hline Population density & -0.055 & 0.002 & 0.027 & -0.060 & 0.738 & -0.054 \\
\hline Organic matter & 0.194 & -0.334 & -0.002 & 0.185 & 0.078 & -0.684 \\
\hline Distance to streams & 0.088 & -0.174 & 0.007 & 0.197 & 0.067 & 0.829 \\
\hline
\end{tabular}

*Forest compactness measured as the perimeter to area ratio of the largest contiguous forest patch within the TRS. Lower values indicate forests, which are more compact. The extraction method was principal component analysis (PCA) and the rotation method was Varimax with Kaiser normaliztion.

segments) were retained and three management variables (state, test intensity and the interaction of these two) were added to the model. The addition of management variables improved the model with AIC reduced to 1,732 and likelihood ratio $\chi^{2}$ of 400 (P $<0.001)$. The third stage of model development involved testing for interactions between testing intensity, state and the environmental covariates and testing for differences in covariate response with the interaction variables. The overall fit of the model improved only modestly by using interactions, but the interaction variable between clay and testing proved more important than the variable for clay alone. Intensity by state was also important. None of the other interactions proved important.

The model residuals of model 3 had strong spatial autocorrelation ( $\mathrm{I}=0.321 ; \mathrm{P}<0.01)$. In the fourth stage, a spatial lag variable for the total number of cases was developed measured as the average number of cases each TRS had in its surrounding TRS based on a queen's case neighbourhood. This measured the potential influence of the number of cases in neighbouring TRS on each TRS, itself. The addition of the CWD cases spatial lag variable improved the model fit considerably, with the AIC reduced to 1,464. The final stage of model development involved testing for the effect of spatial lag on each of the environmental covariates. The final model with the important environmental covariates, management factors, interaction terms and significant spatial lag variables had an AIC of 1,437 . The residual autocorrelation was reduced considerably to $\mathrm{I}=0.068(\mathrm{P}<0.01)$ with the inclusion of spatial variables.

The final model included five landscape variables and three management variables (Table 4). Large forest size (factor 3), lower elevation areas closer to large rivers (factor 4), and TRS with a combination of less agriculture, more forest and more forest compactness (factor 1 ) were associated with more CWD. Less clay soil indicated an increase in CWD, but this effect was not significant in the model after including the interaction of intensive testing and clay. In other words, lower clay content was associated with CWD primarily in places where more intensive testing was carried out. The number of forest segments was an important variable in the third stage of the model, but it was not significant with the inclusion of its lagged variable, while the lagged variable improved the model. More specifically, fewer forest segments in the TRS surrounding the target TRS was associated with more CWD, but not the forest segments in the TRS, itself. Compared to Wisconsin, the TRS in Illinois had less chance for cases of CWD, after controlling for the other variables. However, the places in Illinois where more testing was carried out were associated with increased number of cases of CWD compared to the similarly tested places in Wisconsin. In terms of the other spatially lagged variables, those for factors 1, 3 and 4 all contributed significantly to the model. 
Table 4. Parameter estimates for the final negative binomial model.

\begin{tabular}{|c|c|c|c|c|c|c|c|}
\hline \multirow{2}{*}{ Parameter } & \multirow{2}{*}{ B } & \multirow{2}{*}{$\begin{array}{l}\text { Standard } \\
\text { error } 95 \%\end{array}$} & \multicolumn{2}{|c|}{ Wald confidence interval } & \multicolumn{3}{|c|}{ Hypothesis test } \\
\hline & & & Lower & Upper & Wald $\chi^{2}$ & $\mathrm{df}$ & $\mathrm{P}$ \\
\hline (Intercept) & -2.283 & 0.319 & -2.909 & -1.657 & 51.10 & 1 & $<0.001$ \\
\hline Factor 1 & 0.327 & 0.098 & 0.136 & 0.518 & 11.24 & 1 & $<0.001$ \\
\hline Factor 3 & 0.294 & 0.113 & 0.074 & 0.515 & 6.83 & 1 & 0.009 \\
\hline Factor 4 & -0.574 & 0.289 & -1.141 & -0.008 & 3.95 & 1 & 0.045 \\
\hline Intensity by clay & -0.081 & 0.042 & -0.163 & 0.002 & 3.69 & 1 & 0.056 \\
\hline State $(\mathrm{IL}=1)$ & -1.073 & 0.283 & -1.628 & -0.518 & 14.37 & 1 & $<0.001$ \\
\hline Test intensity $(>12=1)$ & 1.824 & 0.537 & 0.773 & 2.876 & 11.56 & 1 & $<0.001$ \\
\hline Intensity by state & 1.283 & 0.349 & 0.599 & 1.966 & 13.52 & 1 & $<0.001$ \\
\hline \multicolumn{8}{|l|}{ Lag variables } \\
\hline CWD cases & 1.275 & 0.104 & 1.072 & 1.479 & 151.11 & 1 & $<0.001$ \\
\hline Factor 1 & -0.711 & 0.188 & -1.079 & -0.343 & 14.36 & 1 & $<0.001$ \\
\hline Factor 3 & -0.642 & 0.195 & -1.023 & -0.260 & 10.88 & 1 & $<0.001$ \\
\hline Factor 4 & 0.901 & 0.350 & 0.214 & 1.587 & 6.61 & 1 & 0.010 \\
\hline No. of forest segments & -0.607 & 0.154 & -0.908 & -0.306 & 15.59 & 1 & $<0.001$ \\
\hline (Scale) & $1.177^{\mathrm{a}}$ & & & & & & \\
\hline (Negative binomial) & $1^{\mathrm{b}}$ & & & & & & \\
\hline
\end{tabular}

${ }^{a}$ Computed based on the Pearson $\chi^{2}$; bfixed at the displayed value. The response variable was number of positive tests for CWD. The offset variable was the probability of deer in a TRS. The analysis was on the analysis subset, $\mathrm{N}=2,555$ TRS. The Akaike's information criterion (AIC) was 1,437 . The omnibus test likelihood ratio $\chi^{2}$ value was 297 ( $\mathrm{df}=12 ; \mathrm{P}<0.001$ ).

\section{Outcome evaluation}

The mean predicted value from the regression model of the number of cases of CWD by TRS was 0.444 (SD $=12.15)$. Predicted values had a range of from 0 to 605.7 , but the highest values were outliers. All but 10 TRS had predicted values of 7 or less, with these 10 found in the core area of CWD, where CWD was generally over predicted by the model (Fig. 4). For evaluation purposes, the predicted values were assigned to four classes based on percentiles with class limits of 0.012 (10\%), $0.034(50 \%)$ and 0.233 (90\%) (Table 5, Fig. 4). Of the cases reported during the period from 2003 to 2009 , about $91 \%$ of the cases were located in a TRS within the top two prediction classes, within an area that was $32 \%$ of the study area. Of the 58 cases from 2010 and 44 cases from 2011 reported in the study region, $93 \%$ were in TRS in the top two classes in 2010 and $80 \%$ in 2011 , or about $87 \%$ overall. The percentage of positive tests during the period from

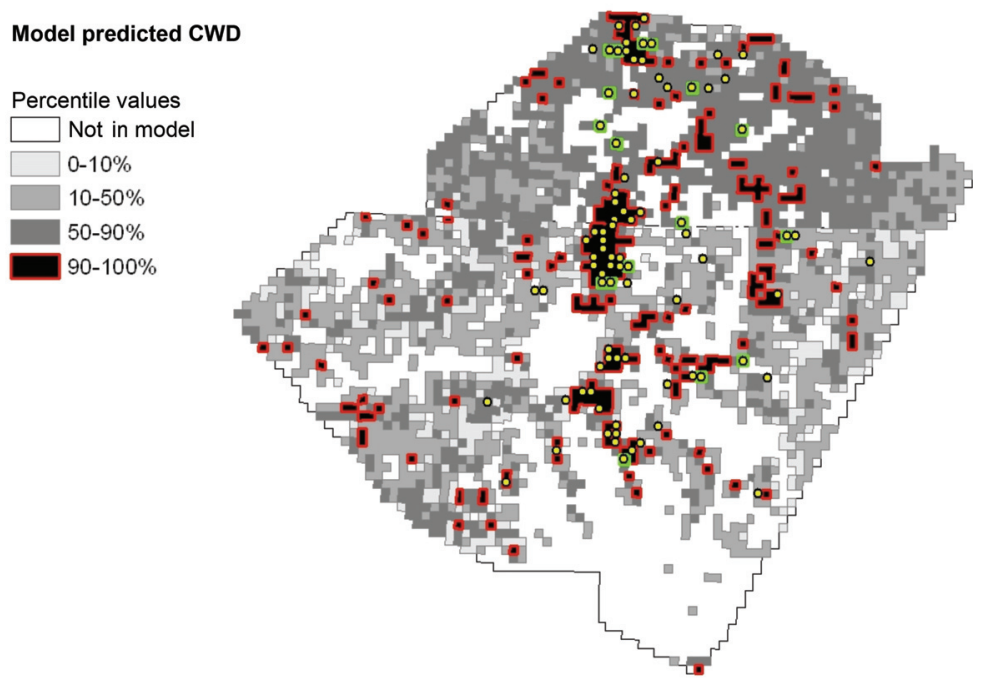

Fig. 4. Predicted number of cases per TRS based on the negative binomial model for the years from 2003 to 2009 and new case locations (yellow circles) reported in 2010 and 2011. Green boxes around the yellow circle indicate a TRS with a case where testing was less than 13 tests during the study period and the TRS was in one of the two highest prediction classes. The break values for the percentiles were $0.0122(10 \%), 0.0343(50 \%)$ and $0.2331(90 \%)$. 
Table 5. Predicted number of CWD cases from the regression model relative to key environmental factors.

\begin{tabular}{|c|c|c|c|c|c|}
\hline CWD model prediction class & $\begin{array}{c}0 \\
\text { (not in model) }\end{array}$ & $\begin{array}{c}1 \\
(\leq 0.012)\end{array}$ & $\begin{array}{c}2 \\
(0.012-0.034)\end{array}$ & $\begin{array}{c}3 \\
0.034-0.233)\end{array}$ & $\begin{array}{c}4 \\
(>0.233)\end{array}$ \\
\hline TRS (N) & 1,424 & 250 & 1,025 & 1,026 & 254 \\
\hline \multicolumn{6}{|l|}{ Deer characteristics } \\
\hline CWD cases 2003-2009 & 15 & 2 & 18 & 86 & 261 \\
\hline$\%$ positive tests $2003-2009$ & 0.45 & 0.11 & 0.42 & 0.89 & 2.98 \\
\hline Cases 2010 & 2 & 0 & 2 & 20 & 34 \\
\hline Cases 2011 & 1 & 1 & 7 & 10 & 25 \\
\hline Average deer probability & 4.2 & 33.3 & 36.6 & 48.2 & 56.9 \\
\hline \multicolumn{6}{|l|}{ Land cover and forest } \\
\hline$\%$ agriculture & 79.9 & 73.8 & 75.5 & 65.0 & 56.5 \\
\hline$\%$ forest & 1.1 & 8.7 & 10.3 & 19.0 & 28.3 \\
\hline $\mathrm{N}$ forest segments $/ \mathrm{km}^{2}$ & 0.70 & 2.25 & 1.90 & 1.81 & 1.47 \\
\hline Forest perimeter to area & 14.9 & 14.5 & 13.4 & 10.6 & 8.8 \\
\hline Maximum forest size & 0.6 & 16.3 & 8.9 & 16.0 & 14.2 \\
\hline Average elevation & 263 & 253 & 258 & 265 & 262 \\
\hline Distance from large rivers & 5,704 & 4,218 & 4,932 & 4,943 & 5,009 \\
\hline \multicolumn{6}{|l|}{ Human population } \\
\hline$\%$ urban & 12.5 & 7.2 & 5.1 & 4.4 & 4.1 \\
\hline Population density & 438 & 283 & 302 & 303 & 258 \\
\hline \multicolumn{6}{|l|}{ Soils } \\
\hline Clay & 14.4 & 13.81 & 13.85 & 12.54 & 12.19 \\
\hline Sand & 9.4 & 13.98 & 13.50 & 17.68 & 16.34 \\
\hline Organic & 2.9 & 2.89 & 3.21 & 3.13 & 2.81 \\
\hline $\mathrm{pH}$ & 6.51 & 6.54 & 6.53 & 6.55 & 6.57 \\
\hline
\end{tabular}

With the exception of the variables Pop density $(\mathrm{P}=0.086)$ and $\mathrm{pH}(\mathrm{P}=0.066)$, all of the variables listed were tested with ANOVA and differences in means between the groups 1 to 4 , combined, were significant at $\mathrm{P}<0.05$. The classes are based on percentiles of $10 \%, 50 \%, 90 \%$ and $100 \%$.

2003 to 2009 was distinctly higher $(2.98 \%)$ in the highest prediction class compared to the lowest class $(0.11 \%)$. Three cases reported in 2010 or 2011 were found in a TRS outside the model subset area.

Finally, the CWD model case predictions were described relative to visible or measurable landscape characteristics (Table 5). Differences in environmental factors compared to the four classes of CWD risk and a fifth comparison class of the TRS outside the model subset were tested using ANOVA. Several environmental variables increased or decreased linearly with increased probability of CWD. The percentage of agriculture, urban land and forest, forest compactness and the percentage of clay soils follow this pattern. For example, the percentage of agricultural in a TRS outside the models was $79.9 \%$. It declined steadily from $73.8 \%$ to $56.5 \%$ across risk classes, with the lowest value found in the areas with the highest risk of CWD. The average percentage of forest in the area outside the model was only $1.1 \%$, while prediction class 4 , with the highest probability of CWD had $28.3 \%$ forest. Urban land use was less common in high CWD risk areas and the forests in high CWD risk areas are more compact. Clay soils were most dominant in areas outside the model and least present in the higher CWD risk areas.

Other landscape characteristics did not have a clear linear relationship with CWD risk but still had distinct patterns relative to the classes of risk, indicating the possibility of a threshold value or other relationship being important. The percentage of sandy soils, for example was distinctly lower outside the model area at 9.4\% compared to the four classes of CWD risk, which ranged from $14.0 \%$ to $17.7 \%$ sand. More sand was associated with more CWD, and the two highest classes $(17.7 \%$ and $16.3 \%)$ were distinctly higher than the lower two risk classes $(13.8 \%$ and $13.9 \%)$. The soil variable that measured organic matter was highest in the two middle classes of CWD risk, with the lowest and highest classes having similar and lower levels, and soil $\mathrm{pH}$ was higher in the highest CWD class, lowest in the area outside the model, but not distinctive between the $1^{\text {st }}$ through $3^{\text {rd }}$ class of CWD risk. The distance from large rivers was higher for risk class 4 than for risk class 1 , but the area outside the model had the highest distance of all 5 classes, so this variable was associated with increased risk only relative to the model subset region. 


\section{Discussion}

The reported cases of CWD in the Illinois and Wisconsin region of the USA are clustered geographically, indicating that environmental factors may constrain or enhance the persistence and transmission of CWD among white-tailed deer. Bias in sampling of deer tested for CWD infections and used for spatial epidemiology analysis may affect spatial patterns and model outcomes (Conner et al., 2000; Osnas et al., 2009). Access to land for removal of deer through any method is variable, and both public and private land may be either accessible or not, making a patchwork of accessibility that is highly localised, and greatly complicating the ability to gather representative samples (Nusser et al., 2008). In our analysis, the quantity of cases was more locally clustered than the pattern of percentage of positive tests, with smaller areas of a few contiguous TRS having high numbers of reported cases, but larger areas having generally high prevalence. Likely the broader pattern more closely resembles the true pattern of the disease, as the reported cases are based on harvesting locations and intensive culling in high-risk areas can result in relatively large numbers of diseased animals (Mateus-Pinilla et al., 2013).

CWD risk locations changed over time. The spacetime pattern analysis indicated that more recent clusters of high numbers of CWD formed towards the northern part of the study area in and near Wisconsin. Additionally, some of the space-time clusters identified as starting in the middle period were long enough to continue to the end of the study period (2009), and they may persist beyond this time. The sex and age of deer needed to be considered in this spatial analysis, because culling may result in a higher percentage of fawn and doe kills than hunting (Wasserberg et al., 2009; Mateus-Pinilla et al., 2013). In the IllinoisWisconsin study area, there was a higher rate of CWD in adult deer $(1.93 \%)$ than in yearlings $(0.89 \%)$ and than in fawns $(0.45 \%)$. The differences in CWD rate by age were significant (ANOVA: df 2, 28,77, $\mathrm{F}=41.37, \mathrm{P}<0.001)$ and differences were seen between all groups using multiple comparisons. Male deer had a higher rate of CWD in the study area, but the difference was marginally significant (ANOVA; $\mathrm{df}=1, \mathrm{~F}=3.09, \mathrm{P}=0.079)$. The space-time clustering was measured while controlling for covariates related to the sex and age of deer to avoid the effects of sampling bias. Thus, though sex may be related to harvest method and the risk of CWD varies by sex and age, the clustering of cases was measurable while controlling for those characteristics of the tested population.
We have mitigated the effect of these potential biases in the landscape regression model in several ways. We used the deer probability as an offset variable in the regression as a proxy for population and removed the outlier areas where a deer might have been reported with CWD but where habitat characteristics were not suitable for supporting deer. This is more rigorous than to use only the test locations to estimate deer populations and reduces, for example, the effect of a higher percentage of positive cases being found where older deer were sampled more heavily. This measure of deer probability was based on landscape features, and though the input was a result of testing, the absolute number of tests was not directly related to the probability value. We also included the variables related to the intensity of testing and the state in which the test was carried out. We recognise that the small number of CWD positive tests and the lack of spatially and temporally robust demographic data on deer populations limited the discriminating power of the analysis, but with these statistical measures in place, we improved our ability to consider the landscape variables in this context.

The Wisconsin and Illinois Departments of Natural Resources have focused on removal of deer to reduce CWD, but each state has made decisions based on funding levels, constituent feedback and interpretation of scientific studies. Both states have used deer reduction programmes and issuance of more hunting permits to reduce deer herd size. The Illinois DNR has relied on focused culling and has been carrying this out consistently across years (IDNR, 2011; Mateus-Pinilla et al., 2013). In Wisconsin, some deer reduction policies have met with resistance (WDNR, 2011). The regression analysis showed that Illinois had lower risk for CWD overall. But TRS with more intensive testing ( $>12$ tests during the study period) had higher predicted CWD and based on the interaction term between testing and state, Illinois had even higher CWD in TRS tested intensely than Wisconsin. So though Illinois may have very locally high reported case counts, differences in management approaches and deer reduction policies in combination with environmental factors were related to the lower levels of CWD risk in Illinois. Looking at the outbreak across state lines illustrates the potential for different patterns observable from different statelevel policies. Based on our results, a continued focus of intensive management on specific areas with prior CWD is a valid disease management strategy.

The analysis of the location of predicted CWD-positive TRS relative to landscape and management characteristics provides insight to possible transmission dynamics and enables the creation of maps that give 
further guidance regarding areas where CWD management efforts should be intensified or safely reduced. A spatial model of risk for disease transmission can be useful to target response efforts and to provide a rationale for the funding needed to monitor areas of higher potential for disease. We identified 17 TRS where the CWD risk was relatively high but intensity of testing was relatively low (Fig. 4). The location of these TRS was often near TRS with earlier cases, confirming the value of testing and control near known CWD cases. The average deer probability for these 17 TRS was almost $48 \%$ (a relatively high value), but some of these TRS were surrounded by TRS where deer probability was generally low, indicating that these high-risk areas, though outside of core deer habitat, should still be considered for increased surveillance and control.

Less clay in soils was generally related to areas with higher predicted CWD, but this difference overall was more pronounced in places where more testing had been carried out. Recent research indicated CWD risk was associated with increased clay soils in Colorado (Walter et al., 2011), corresponding to laboratorybased studies where clay soils have higher PrP sorption capacity (Jonson et al., 2006). Field-based studies of scrapie in Great Britain have found inconclusive or the opposite effects with clay soils (Imrie et al., 2009; Saunders et al., 2012). We suggest that in this region, less clay in soils may be related to factors favouring increased deer density and the CWD focal areas may be in places where transmission is occurring mostly through contact with infectious animals and the density effect overwhelms the possible effect of prions persistence in soils. For this study area, the scale of the analysis did not provide evidence of field conditions related to prion infectivity being promoted by clay soils, but this may be found in other environmental settings or different analysis scales. Sand in soils was not a significant variable in the multivariate analysis but had a negative relationship with CWD risk. Our results suggest a threshold value of $14 \%$ may distinguish the differences between higher and lower CWD areas. The effect of soil $\mathrm{pH}$ was small, and it was not significant in the regression model; but taken alone, there was evidence that $\mathrm{pH}$ closer to neutral (i.e. less acidic) had discriminating power relative to CWD risk. The calculation of TRS-based smoothed values of $\mathrm{pH}$ in soils reduced the range of variability considerably. The scale of the measure of the TRS was particularly problematic in this case. The relationship with organic matter was inconclusive. More precisely designed data collection and analysis may help to elu- cidate the role of soils in CWD transmission in natural settings, as these factors played an important role in this model of CWD risk.

Large, compact continuous forest patches were associated with both higher CWD risk and higher probability of deer. Large forests are generally associated with deer habitat in this area (Nixon et al., 1988). The potential for an area to support deer is not defined precisely. About $80 \%$ of landscapes outside the most urban counties could be considered optimal or usable habitat, with about $50 \%$ of the landscape useful year-round as deer habitat (Roseberry and Woolf, 1998). The forest patches in this region that are situated at about $5 \mathrm{~km}$ distance from large rivers are particularly more likely to have higher CWD risk. During winter, deer may be present in higher density in closed canopy upland forest, while in other seasons, they favour agricultural and forest edges. The variables associated with both deer habitat and increased CWD risk may be places where landscape feature favour high deer density rather than with distinct environmental features related to CWD persistence.

Recent adaption to dynamic suburban and exurban landscapes also makes generalisations across landscape types difficult (Nixon et al., 1991; Storm et al., 2007). The TRS that were highly urban were clearly at lower risk for CWD and had lower probability of deer populations. The differences outside the most urban areas was not as clear however, and the density of human population was somewhat higher in the $3^{\text {rd }}$ class of CWD risk compared to the lowest class (Table $5)$, indicating the presence of exurban forested CWD risk areas, which may need to be considered for deer removal beyond ordinary hunting, given that hunting access is less in these areas compared to places farther from residential areas.

The map of predicted CWD should be interpreted keeping in mind the scale of the analysis at the TRS level, which hides the variability within a TRS. The areas identified as having landscape characteristics most associated with CWD are useful to generate further hypotheses regarding transmission of CWD in free-ranging deer, but deer can travel from those areas, so harvest and testing should not be limited strictly to those places. In particular, we see a need to discern between landscape conditions that increase risk due to higher concentrations of deer compared to risk related to environmental transmission due to persistence of infectious prions in the environment. While related to each other and possibly associated with similar landscape characteristics of soils, vegetation and forests, better discernment between these would allow for more focused intervention strategies. 


\section{Acknowledgements}

The Illinois Department of Natural Resources, the United States Geological Survey, United States Department of Agriculture and the US Fish and Wildlife Service Federal Aid in Wildlife Restoration Project W-146-R provided funds for this work. Paul Shelton at the Illinois Department of Natural Resources provided insight on the collection of data on CWD in Illinois.

\section{References}

Angers RC, Browning SR, Seward TS, Sigurdson CJ, Miller MW, Hoover EA, Telling GC, 2006. Prions in skeletal muscles of deer with chronic wasting disease. Science 311, 1117.

Belay ED, Maddox RA, Williams ES, Miller MW, Gambetti P, Schonberger LB, 2004. Chronic wasting disease and potential transmission to humans. Emerg Infect Dis 10, 977-984.

Breslow NE, 1984. Extra-poisson variation in log-linear models. Appl Stat 33, 38-44.

Burnham KP, Anderson DR, 2002. Model selection and multimodel inference: a practical information-theoretic approach. New York: Springer Publishing.

Conner MM, McCarty CW, Miller MW, 2000. Detection of bias in harvest-based estimates of chronic wasting disease prevalence in mule deer. J Wildl Dis 36, 691-699.

Conner MM, Miller MW, 2004. Movement patterns and spatial epidemiology of a prion disease in mule deer population units. Ecol Appl 14, 1870-1881.

Davies P, Brown DR, 2009. Manganese enhances prion protein survival in model soils and increases prion infectivity to cells. PLoS One 4, e7518.

Elith J, Phillips SJ, Hastie T, Dudík M, Chee YE, Yates CJ, 2011. A statistical explanation of MaxEnt for ecologists. Divers Distrib 17, 43-57.

Enserink M, 2001. Prion diseases. U.S. gets tough against chronic wasting disease. Science 294, 978-979.

Gough KC, Maddison BC, 2010. Prion transmission, prion excretion and occurrence in the environment. Prion 4, 275 282.

Haley NJ, Seelig DM, Zabel MD, Telling GC, Hoover EA, 2009. Detection of CWD prions in urine and saliva of deer by transgenic mouse bioassay. PLoS One 4, e4848.

IDNR (Illinois Department of Natural Resources), 2011. Chronic Wasting Disease. Available at: http://www.dnr.state.il. us/cwd/ (accessed on February 2013).

Imrie CE, Korre A, Munoz-Melendez G, 2009. Spatial correlation between the prevalence of transmissible spongiform diseases and British soil geochemistry. Environ Geochem Health 31, 133-145.

Jacobson KH, Lee S, Somerville RA, McKenzie D, Benson CH, Pedersen JA, 2010. Transport of the pathogenic prion protein through soils. J Environ Qual 39, 1145-1152.
Johnson CJ, Phillips KE, Schramm PT, McKenzie D, Aiken JM, Pedersen JA, 2006. Prions adhere to soil minerals and remain infectious. PLoS Pathog 2, e32.

Joly DO, Ribic CA, Langenberg JA, Beheler K, Batha CA, Dhuey BJ, Rolley RE, Bartelt G, Van Deelen TR, Samuel MD, 2003. Chronic wasting disease in free-ranging Wisconsin white-tailed deer. Emerg Infect Dis 9, 599-601.

Joly DO, Samuel MD, Langenberg JA, Blanchong JA, Batha CA, Rolley RE, Keane DP, Ribic CA, 2006. Spatial epidemiology of chronic wasting disease in Wisconsin white-tailed deer. J Wildl Dis 42, 578-588.

Joly DO, Samuel MD, Langenberg JA, Rolley RE, Keane DP, 2009. Surveillance to detect chronic wasting disease in whitetailed deer in Wisconsin. J Wildl Dis 45, 989-997.

Kelly AC, Mateus-Pinilla NE, Diffendorfer J, Jewell E, Ruiz MO, Killefer J, Shelton P, Beissel T, Novakofski J, 2008. Prion sequence polymorphisms and chronic wasting disease resistance in Illinois white-tailed deer (Odocoileus virginianus). Prion 2, 28-36.

Kulldorff M, 1997. A spatial scan statistic. Commun Stat Theory 26, 1481-1496.

Legendre P, Legendre L, 1998. Numerical ecology. Amsterdam: Elsevier Science.

Leita L, Fornasier F, De Nobili M, Bertoli A, Genovesi S, Sequi $\mathrm{P}, 2006$. Interactions of prion proteins with soil. Soil Biol Biochem 38, 1638-1644.

Ma X, Benson CH, McKenzie D, Aiken JM, Pedersen JA, 2007. Adsorption of pathogenic prion protein to quartz sand. Environ Sci Technol 41, 2324-2330.

Maddison BC, Baker CA, Terry LA, Bellworthy SJ, Thorne L, Rees HC, Gough KC, 2010. Environmental sources of scrapie prions. J Virol 84, 11560-11562.

Mateus-Pinilla N, Weng H-Y, Ruiz MO, Shelton P, Novakofski J, 2013. Evaluation of a wild white-tailed deer population management program for controlling chronic wasting disease in Illinois, 2003-2008. Prev Vet Med 110, 541-548.

Mathiason CK, Powers JG, Dahmes SJ, Osborn DA, Miller KV, Warren RJ, Mason GL, Hays SA, Hayes-Klug J, Seelig DM et al., 2006. Infectious prions in the saliva and blood of deer with chronic wasting disease. Science 314, 133-136.

Miller MW, Conner MM, 2005. Epidemiology of chronic wasting disease in free-ranging mule deer, spatial, temporal, and demographic influences on observed prevalence patterns. J Wildl Dis 41, 275-290.

Miller MW, Williams ES, 2003. Prion disease, horizontal prion transmission in mule deer. Nature 425, 35-36.

Miller MW, Williams ES, Hobbs NT, Wolfe LL, 2004. Environmental sources of prion transmission in mule deer. Emerg Infect Dis 10, 1003-1006.

Millhauser GL, 2007. Copper and the prion protein, methods, structures, function, and disease. Annu Rev Phys Chem 58, 299-320. 
Nixon CM, Hansen LP, Brewer PA, 1988. Characteristics of winter habitats used by deer in Illinois. J Wildl Manag 52, 552-555.

Nixon CM, Hansen LP, Brewer PA, Chelsvig JE, 1991. Ecology of white-tailed deer in an intensively farmed region of Illinois. Wildlife Monogr 118, 3-77.

Nusser SM, Clark WR, Otis DL, Huang L, 2008. Sampling considerations for disease surveillance in wildlife populations. J Wildl Manag 72, 52-60.

Osnas EE, Heisey DM, Rolley RE, Samuel MD, 2009. Spatial and temporal patterns of chronic wasting disease, fine-scale mapping of a wildlife epidemic in Wisconsin. Ecol Appl 19, 1311-1322.

Peterson AT, 2006. Uses and requirements of ecological niche models and related distributional models. Biodivers Inf 3, 59-72.

Roseberry JL, Woolf A, 1998. Habitat-population density relationships for white-tailed deer in Illinois. Wildlife Soc B 26, 252-258.

Saunders SE, Bartelt-Hunt SL, Bartz JC, 2008. Prions in the environment Occurrence, fate and mitigation. Prion 2, 162169.

Saunders SE, Bartz JC, Bartelt-Hunt SL, 2012. Soil-mediated prion transmission, is local soil-type a key determinant of prion disease incidence? Chemosphere 87, 661-667.

Saunders SE, Bartz JC, Vercauteren KC, Bartelt-Hunt SL, 2010. Enzymatic digestion of chronic wasting disease prions bound to soil. Environ Sci Technol 44, 4129-4135.

Seidel B, Thomzig A, Buschmann A, Groschup MH, Peters R, Beekes M, Terytze K, 2007. Scrapie agent (strain 263K) can transmit disease via the oral route after persistence in soil over years. PLoS One 2, e435.

Sigurdson CJ, 2008. A prion disease of cervids, chronic wasting disease. Vet Res 39, 41.

Sigurdson CJ, Williams ES, Miller MW, Spraker TR, O'Rourke
KI, Hoover EA, 1999. Oral transmission and early lymphoid tropism of chronic wasting disease PrPres in mule deer fawns (Odocoileus hemionus). J Gen Virol 80, 2757-2764.

Spraker TR, Miller MW, Williams ES, Getzy DM, Adrian WJ, Schoonveld GG, Spowart RA, O’Rourke KI, Miller JM, Merz PA, 1997. Spongiform encephalopathy in free-ranging mule deer (Odocoileus hemionus), white-tailed deer (Odocoileus virginianus) and Rocky Mountain elk (Cervus elaphus nelsoni) in northcentral Colorado. J Wildl Dis 33, 1-6.

Storm DJ, Nielsen CK, Schauber EM, Woolf A, 2007. Space use and survival of white-tailed deer in an exurban landscape. J Wildl Manag 71, 1170-1176.

Tamgüney G, Miller MW, Wolfe LL, Sirochman TM, Glidden DV, Palmer C, Lemus A, DeArmond SJ, Prusiner SB, 2009. Asymptomatic deer excrete infectious prions in faeces. Nature 461, 529-532.

USGS (United States Geological Survey), 2012. Chronic wasting disease. Madison: National Wildlife Health Center, 2011. http://www.nwhc.usgs.gov/disease_information/chronic_wasting_disease/ (accessed on February 2013).

Walter WD, Walsh DP, Farnsworth ML, Windelman DL, Miller MW, 2011. Soil clay content underlies prion infection odds. Nat Commun 2, 200.

Wasserberg G, Osnas EE, Rolley RE, Samuel MD, 2009. Host culling as an adaptive management tool for chronic wasting disease in white-tailed deer, a modelling study. J Appl Ecol 46, 457-466.

Williams ES, 2005. Chronic wasting disease. Vet Pathol 42, 530-549.

Williams ES, Young S, 1980. Chronic wasting disease of captive mule deer, a spongiform encephalopathy. J Wildl Dis 16, 89-98. WDNR (Wisconsin Department of Natural Resources), 2011. Wisconsin's Chronic Wasting Disease Response Plan: 20102025. Available at: http://dnr.wi.gov/org/land/wildlife/whealth /issues/CWD/plan.htm (accessed on February 2013). 